\title{
GRAF KOPRIMA DARI SUBGRUP DI GRUP SIMETRI
}

\author{
REFI ALKADAR, YANITA*,DES WELYYANTI \\ Program Studi S1 Matematika, \\ Fakultas Matematika dan Ilmu Pengetahuan Alam, Universitas Andalas, \\ Kampus UNAND Limau Manis Padang, Indonesia. \\ email : refialqodarr@gmail.com
}

Diterima 15 Desember 2020 Direvisi 29 Desember 2020 Dipublikasikan 12 Januari 2021

\begin{abstract}
Abstrak. Perkembangan studi tentang keterkaitan antara struktur aljabar dengan teori graf telah membuahkan banyak hasil, salah satunya adalah graf koprima. Misalkan $T_{G}$ adalah graf koprima dari grup berhingga $G$. Himpunan titik dari $T_{G}$ adalah semua unsur dari grup $G$, dan dua titik yang berbeda $x, y$ di $G$ dikatakan bertetangga jika dan hanya jika $f p b(|x|,|y|)=1$. Pada makalah ini akan ditentukan karakteristik graf koprima dari subgrup di grup simetri. Metode yang digunakan adalah studi literatur dan analisis dilakukan dengan melihat pola graf koprima yang dibangun dari semua subgrup di grup simetri- $n$ dengan $2 \leq n \leq 4$. Adapun hasil yang diperoleh adalah setiap subgrup yang berorde hasil perkalian dari dua bilangan prima yang berbeda membentuk graf 3-partit lengkap, dan setiap subgrup yang memiliki unsur-unsur berorde sama atau kelipatannya membentuk graf bintang.
\end{abstract}

Kata Kunci: Graf Koprima, Grup Simetri

\section{Pendahuluan}

Matematika merupakan abstraksi dari dunia nyata yang ditulis dalam bentuk bahasa simbol. Bahasan yang terdapat dalam matematika tersusun dengan rapi. Pemahaman suatu konsep akan mempengaruhi pemahaman pada konsep berikutnya yang berkaitan. Selain pemahaman konsep yang berkaitan, terdapat juga keterkaitan antara cabang matematika salah satunya adalah kerterkaitan antara struktur aljabar dengan teori graf yang telah membuahkan banyak hasil terbaru dan menarik dalam literatur, salah satunya adalah graf koprima.

Konsep graf koprima telah diperkenalkan oleh Sattanathan dan Kala yang mereka sebut order prime graphs of finite groups atau orde graf prima dari grup berhingga [9]. Lalu graf ini berkembang dan menjadi graf koprima dari grup. Graf koprima didefinisikan sebagai suatu graf yang dibangun oleh unsur-unsur dalam suatu himpunan tak kosong berhingga pada suatu grup dimana dua unsur dikatakan

*penulis korespondensi 
bertetangga (adjacent) jika dan hanya jika faktor persekutuan terbesar dari orde kedua unsur tersebut adalah satu [8].

Struktur aljabar dan teori graf merupakan dua bahasan yang perlu dikaji oleh mahasiswa matematika. Keterkaitan antara keduanya menjadi topik yang menarik untuk dikaji secara lebih rinci. Karakteristik graf yang dibentuk merupakan aspek yang akan diamati. Kajian tentang grup simetri terkait graf dikaji oleh [6], yaitu graf konjugasi dari grup simetri yang membuahkan hasil: unsur-unsur yang memiliki tipe cycle sama saling berkonjugasi sehingga berada pada satu kelas konjugasi serta membentuk graf komplit. Kajian graf koprima terkait grup dikaji oleh [10], yaitu graf koprima dari grup dihedral yang membuahkan hasil: jika $n$ bilangan prima, maka graf koprima dari $D_{2 n}$ adalah graf bipartit.

\section{Tinjauan Pustaka}

Dalam makalah ini, grup yang akan digunakan adalah grup simetri- $n$. Grup simetri$n$ adalah himpunan semua permutasi dari suatu himpunan dengan $n$ unsur. Suatu permutasi dari himpunan berhingga dapat ditulis sebagai sebuah cycle atau sebuah produk dari cycle saling lepas.

Orde dari suatu grup $G$, dinotasikan sebagai $|G|$, adalah banyaknya unsur dari $G$. Orde dari suatu unsur $g$ di grup $G$, dinotasikan sebagai $|g|$, adalah bilangan bulat positif terkecil $n$ sedemikian sehingga $g^{n}=e$ dimana $e$ adalah unsur identitas di $G$. Orde dari suatu unsur di grup simetri- $n$ dapat dengan mudah ditentukan dengan Teorema 3.6 pada [2]. Pada makalah ini, teorema Lagrange dan teorema Cauchy juga digunakan pada pembuktian Proposisi 4.1. Teorema Lagrange menyatakan bahwa jika $H$ adalah subgrup dari grup berhingga $G$, maka orde $H$ membagi orde $G$. Secara khusus, orde $x$ membagi orde $G$ untuk setiap elemen $x$ di $G$. Teorema Cauchy menyatakan bahwa misalkan $G$ suatu grup berhingga dan $p$ suatu bilangan prima. Jika $p$ habis membagi $|G|$, maka $G$ memuat unsur yang berorde $p$. Penjelasan lebih lengkap tentang teori grup dapat dilihat pada [3], [5], dan [7].

Pada makalah ini, graf yang akan diperhatikan adalah graf sederhana yang tak berarah artinya graf tanpa loop maupun sisi ganda. Misalkan $T$ adalah suatu graf, $V(T)$ dan $E(T)$ notasi dari himpunan titik dan sisi dari $T$. Derajat dari suatu titik $v$ di $T$ adalah banyaknya sisi yang terkait dengan $v$. Graf dengan $n+1$ titik dimana 1 titik berderajat $n$ sebagai titik pusat, dan $n$ titik berderajat 1 sebagai daun disebut sebagai graf bintang yang dinotasikan sebagai $K_{1, n}$. Graf yang himpunan titiknya dapat dipartisi menjadi $k$ himpunan tak kosong titik sedemikian sehingga setiap titik di himpunan partisi yang sama tidak bertetangga dan setiap titiknya bertetangga dengan semua titik yang bukan di himpunan partisi yang sama disebut sebagai graf $k$-partit lengkap. Graf $k$-partit lengkap $n$ titik dinotasikan sebagai $T_{k, n}$. Penjelasan lebih lengkap tentang teori graf dapat dilihat pada [1].

\section{Graf Koprima dari Grup Simetri-2, Simetri-3, dan Simetri-4}

Penelitian dilakukan dengan cara mengamati dan menganalisis bentuk graf koprima dari setiap subgrup di grup simetri-2, simetri-3, dan simetri-4 sehingga didapatkan karakteristik graf koprima dari subgrup di grup simetri. 
Unsur-unsur di grup simetri-2 adalah $S_{2}=\left\{\sigma_{0}, \sigma_{1}\right\}$ dengan $\sigma_{0}=(1)$, dan $\sigma_{1}=$ (12). Adapun subgrup-subgrup di grup $S_{2}$ yaitu: $\left\{\sigma_{0}\right\}$, dan $\left\{\sigma_{0}, \sigma_{1}\right\}$. Berdasarkan definisi graf koprima, diperoleh graf koprima dari subgrup di grup simetri-3 yang disajikan pada Tabel 1 berikut.

\begin{tabular}{|c|c|}
\hline Subgrup & Bentuk Graf Koprima \\
\hline$\left\{\sigma_{0}\right\}$ & $\bullet$ \\
\hline$\left\{\sigma_{0}, \sigma_{1}\right\}$ & $\bullet$ \\
\hline
\end{tabular}

Tabel 1. Graf Koprima dari Subgrup di Grup $S_{2}$.

Unsur-unsur di grup simetri-3 adalah $S_{3}=\left\{\sigma_{0}, \sigma_{1}, \sigma_{2}, \sigma_{3}, \sigma_{4}, \sigma_{5}\right\}$ dengan

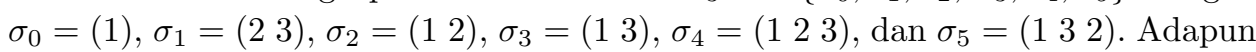
subgrup-subgrup di grup $S_{3}$ yaitu: $\left\{\sigma_{0}\right\},\left\{\sigma_{0}, \sigma_{1}\right\},\left\{\sigma_{0}, \sigma_{2}\right\},\left\{\sigma_{0}, \sigma_{3}\right\},\left\{\sigma_{0}, \sigma_{4}, \sigma_{5}\right\}$, dan $\left\{\sigma_{0}, \sigma_{1}, \sigma_{2}, \sigma_{3}, \sigma_{4}, \sigma_{5}\right\}$. Berdasarkan definisi graf koprima, diperoleh graf koprima dari subgrup di grup simetri-2 yang disajikan pada Tabel 2 berikut.

\begin{tabular}{|c|c|}
\hline Subgrup & Bentuk Graf Koprima \\
\hline$\left\{\sigma_{0}\right\}$ & \\
\hline $\begin{array}{c}\left.\sigma_{0}, \sigma_{1}\right\},\left\{\sigma_{0}, \sigma_{2}\right\} \\
\left\{\sigma_{0}, \sigma_{3}\right\}\end{array}$ & \\
\hline$\left\{\sigma_{0}, \sigma_{4}, \sigma_{5}\right\}$ & \\
\hline$\left\{\sigma_{0}, \sigma_{1}, \sigma_{2}, \sigma_{3}, \sigma_{4}, \sigma_{5}\right\}$ & \\
\hline
\end{tabular}

Tabel 2. Graf Koprima dari Subgrup di Grup $S_{3}$.

Unsur-unsur di grup simetri-4 adalah $S_{4}=\left\{\sigma_{0}, \sigma_{1}, \sigma_{2}, \cdots, \sigma_{23}\right\}$ dengan

$$
\begin{aligned}
& \sigma_{0}=(1), \\
& \sigma_{1}=\left(\begin{array}{ll}
1 & 2
\end{array}\right), \\
& \sigma_{2}=\left(\begin{array}{ll}
1 & 3
\end{array}\right) \text {, } \\
& \sigma_{3}=\left(\begin{array}{ll}
1 & 4
\end{array}\right) \text {, } \\
& \sigma_{4}=\left(\begin{array}{ll}
2 & 3
\end{array}\right) \text {, } \\
& \sigma_{5}=\left(\begin{array}{ll}
2 & 4
\end{array}\right) \text {, } \\
& \sigma_{6}=(34) \text {, } \\
& \sigma_{7}=\left(\begin{array}{lll}
1 & 2
\end{array}\right)\left(\begin{array}{ll}
3 & 4
\end{array}\right) \text {, } \\
& \sigma_{8}=\left(\begin{array}{lll}
1 & 3
\end{array}\right)(24) \text {, } \\
& \sigma_{9}=\left(\begin{array}{lll}
1 & 4
\end{array}\right)\left(\begin{array}{ll}
2 & 3
\end{array}\right) \text {, } \\
& \sigma_{10}=\left(\begin{array}{lll}
1 & 2 & 3
\end{array}\right), \\
& \sigma_{11}=\left(\begin{array}{lll}
1 & 2 & 4
\end{array}\right) \text {, } \\
& \sigma_{12}=\left(\begin{array}{lll}
1 & 3 & 2
\end{array}\right), \\
& \sigma_{13}=\left(\begin{array}{lll}
1 & 3 & 4
\end{array}\right) \text {, } \\
& \sigma_{14}=\left(\begin{array}{lll}
1 & 4 & 2
\end{array}\right) \text {, } \\
& \sigma_{15}=\left(\begin{array}{lll}
1 & 4 & 3
\end{array}\right), \\
& \sigma_{16}=\left(\begin{array}{lll}
2 & 3 & 4
\end{array}\right) \text {, } \\
& \sigma_{17}=\left(\begin{array}{lll}
2 & 4 & 3
\end{array}\right), \\
& \sigma_{18}=\left(\begin{array}{llll}
1 & 2 & 3 & 4
\end{array}\right), \\
& \sigma_{19}=\left(\begin{array}{llll}
1 & 2 & 4 & 3
\end{array}\right),
\end{aligned}
$$


$\sigma_{20}=\left(\begin{array}{llll}1 & 3 & 2 & 4\end{array}\right), \quad \sigma_{21}=\left(\begin{array}{llll}1 & 3 & 4 & 2\end{array}\right), \quad \sigma_{22}=\left(\begin{array}{llll}1 & 4 & 2 & 3\end{array}\right), \quad \sigma_{23}=\left(\begin{array}{llll}1 & 4 & 3 & 2\end{array}\right)$.

Adapun subgrup-subgrup di grup $S_{4}$ yaitu:

$P_{1}=\left\{\sigma_{0}\right\}$,

$P_{2}=\left\{\sigma_{0}, \sigma_{1}\right\}, P_{3}=\left\{\sigma_{0}, \sigma_{2}\right\}, P_{4}=\left\{\sigma_{0}, \sigma_{3}\right\}, P_{5}=\left\{\sigma_{0}, \sigma_{4}\right\}, P_{6}=\left\{\sigma_{0}, \sigma_{5}\right\}$,

$P_{7}=\left\{\sigma_{0}, \sigma_{6}\right\}, P_{8}=\left\{\sigma_{0}, \sigma_{7}\right\}, P_{9}=\left\{\sigma_{0}, \sigma_{8}\right\}, P_{10}=\left\{\sigma_{0} \sigma_{9}\right\}$,

$P_{11}=\left\{\sigma_{0}, \sigma_{10}, \sigma_{12}\right\}, P_{12}=\left\{\sigma_{0}, \sigma_{11}, \sigma_{14}\right\}, P_{13}=\left\{\sigma_{0}, \sigma_{13}, \sigma_{15}\right\}, P_{14}=\left\{\sigma_{0}, \sigma_{16}, \sigma_{17}\right\}$,

$P_{15}=\left\{\sigma_{0}, \sigma_{7}, \sigma_{8}, \sigma_{9}\right\}, P_{16}=\left\{\sigma_{0}, \sigma_{1}, \sigma_{6}, \sigma_{7}\right\}, P_{17}=\left\{\sigma_{0}, \sigma_{2}, \sigma_{5}, \sigma_{8}\right\}, P_{18}=\left\{\sigma_{0}, \sigma_{3}, \sigma_{4}, \sigma_{9}\right\}$,

$P_{19}=\left\{\sigma_{0}, \sigma_{7}, \sigma_{20}, \sigma_{22}\right\}, P_{20}=\left\{\sigma_{0}, \sigma_{8}, \sigma_{18}, \sigma_{23}\right\}, P_{21}=\left\{\sigma_{0}, \sigma_{9}, \sigma_{19}, \sigma_{21}\right\}$,

$P_{22}=\left\{\sigma_{0}, \sigma_{1}, \sigma_{2}, \sigma_{4}, \sigma_{10}, \sigma_{12}\right\}, P_{23}=\left\{\sigma_{0}, \sigma_{1}, \sigma_{3}, \sigma_{5}, \sigma_{11}, \sigma_{14}\right\}$

$P_{24}=\left\{\sigma_{0}, \sigma_{2}, \sigma_{3}, \sigma_{6}, \sigma_{13}, \sigma_{15}\right\}, P_{25}=\left\{\sigma_{0}, \sigma_{4}, \sigma_{5}, \sigma_{6}, \sigma_{16}, \sigma_{17}\right\}$,

$P_{26}=\left\{\sigma_{0}, \sigma_{1}, \sigma_{6}, \sigma_{7}, \sigma_{8}, \sigma_{9}, \sigma_{20}, \sigma_{22}\right\}, P_{27}=\left\{\sigma_{0}, \sigma_{2}, \sigma_{5}, \sigma_{7}, \sigma_{8}, \sigma_{9}, \sigma_{18}, \sigma_{23}\right\}$,

$P_{28}=\left\{\sigma_{0}, \sigma_{3}, \sigma_{4}, \sigma_{7}, \sigma_{8}, \sigma_{9}, \sigma_{19}, \sigma_{21}\right\}$,

$P_{29}=\left\{\sigma_{0}, \sigma_{7}, \sigma_{8}, \sigma_{9}, \sigma_{10}, \sigma_{11}, \sigma_{12}, \sigma_{13}, \sigma_{14}, \sigma_{15}, \sigma_{16}, \sigma_{17}\right\}$,

$P_{30}=S_{4}$.

Berdasarkan definisi graf koprima, diperoleh graf koprima dari subgrup di grup simetri-4 yang disajikan pada Tabel 3 berikut.

\begin{tabular}{|c|c|c|c|}
\hline Subgrup & Bentuk Graf Koprima & Subgrup \\
\hline$P_{1}$ & $\bullet$ & \\
\hline$P_{2}, P_{3}, P_{4}, \ldots, P_{10}$ & & \\
\hline$P_{15}, P_{12}, P_{13}, P_{14}$ & & \\
\hline$P_{15}, P_{16}, P_{17}, \ldots, P_{21}$ & & \\
\hline$P_{29}$
\end{tabular}

Tabel 3. Graf Koprima dari Subgrup di Grup $S_{4}$. 


\section{Karakteristik Graf Koprima dari Subgrup di Grup Simetri}

Berdasarkan pembahasan sebelumnya, didapatkan karakteristik graf koprima dari subgrup di grup simetri yang disajikan pada Tabel 4 berikut.

\begin{tabular}{|l|c|l|}
\hline Subgrup di Grup Simetri- $n$ & $\begin{array}{l}\text { Banyak Unsur } \\
\text { dalam Subgrup }\end{array}$ & Bentuk Graf Koprima \\
\hline \hline \multirow{3}{*}{ Subgrup di grup simetri-2 } & 1 & Graf Trivial \\
\cline { 2 - 3 } & 2 & Graf Bintang $K_{1,1}$ \\
\hline \multirow{4}{*}{ Subgrup di grup simetri-3 } & 1 & Graf Trivial \\
\cline { 2 - 3 } & 2 & Graf Bintang $K_{1,1}$ \\
\cline { 2 - 3 } & 3 & Graf Bintang $K_{1,2}$ \\
\hline \multirow{5}{*}{ Subgrup di grup simetri-4 } & 6 & Graf 3-Partit lengkap $T_{3,6}$ \\
\cline { 2 - 3 } & 1 & Graf Trivial \\
\cline { 2 - 3 } & 2 & Graf Bintang $K_{1,1}$ \\
\cline { 2 - 3 } & 3 & Graf Bintang $K_{1,2}$ \\
\cline { 2 - 3 } & 4 & Graf Bintang $K_{1,3}$ \\
\cline { 2 - 3 } & 6 & Graf 3-Partit lengkap $T_{3,6}$ \\
\cline { 2 - 3 } & 8 & Graf Bintang $K_{1,7}$ \\
\cline { 2 - 3 } & 12 & Graf 3-Partit lengkap $T_{3,12}$ \\
\hline
\end{tabular}

Tabel 4. Karakteristik Graf Koprima dari Subgrup di Grup Simetri.

Berdasarkan Tabel 4, diperoleh dua proposisi berikut.

Proposisi 4.1. (Analog Proposisi 2.8 pada [8]) Misalkan $p$ dan q adalah dua bilangan prima yang berbeda dan $H$ adalah subgrup dari suatu grup simetri-n. Jika $|H|=p q$, maka graf koprima dari $H$ adalah graf 3-partit lengkap $T_{3, p q}$

Bukti. Misalkan $p$ dan $q$ adalah dua bilangan prima yang berbeda dan $H$ adalah suatu subgrup dari grup simetri- $n$ dengan $|H|=p q$. Kemudian, berdasarkan teorema Lagrange diperoleh bahwa setiap orde dari elemen $H$ adalah pembagi dari $p q$ dan berdasarkan teorema Cauchy diperoleh setidaknya ada satu elemen di $H$ sedemikian sehingga ordenya sama dengan $1, p$ atau $q$. Misalkan $U=\{x \in G \mid$ $|x|=p\}$ dan $V=\{y \in G|| y \mid=q\}$. Lalu, karena $p, q$ bilangan prima yang berbeda maka tidak ada bilangan bulat positif selain 1 yang sekaligus habis membagi $p$ dan $q$ artinya $f p b(p, q)=1$. Akibatnya, setiap elemen di $U$ bertetangga dengan setiap elemen di $V$. Perhatikan bahwa $U$ dan $V$ adalah himpunan saling bebas. Jadi $U, V$ dan $\{(1)\}$ adalah himpunan partisi graf koprima dari subgrup $H$, dan karenanya graf koprima dari subgrup $H$ adalah graf 3-partit lengkap $T_{3, p q}$.

Proposisi 4.2. Misalkan $H$ subgrup dari grup simetri-n, $H \neq\{(1)\}$ dengan (1) adalah unsur identitas di grup simetri. Jika untuk setiap $x, y \in H-\{(1)\}$ dengan $|y| \leq|x|$ terdapat $k \in \mathbb{N}$ sedemikian sehingga $|x|=k|y|$, maka graf koprima dari $H$ adalah graf bintang $K_{1,|H|-1}$. 
Bukti. Misalkan $H$ subgrup dari grup simetri- $n, H \neq\{(1)\}$ dengan (1) adalah unsur identitas di grup simetri, dan untuk setiap $x, y \in H-\{(1)\}$ dengan $|y| \leq|x|$ terdapat $k \in \mathbb{N}$ sedemikian sehingga $|x|=k|y|$. Misalkan $T_{H}$ adalah graf koprima dari $H$, akan ditunjukkan bahwa $T_{H}$ adalah graf bintang .

Perhatikan bahwa $x, y \in H-\{(1)\}$ dan $H-\{(1)\}$ sehingga diperoleh $x \neq(1)$ dan $y \neq(1)$ akibatnya $|x| \neq 1$ dan $|y| \neq 1$. Oleh karena $|y| \leq|x|$ dan $|x|=k|y|$ untuk suatu $k \in \mathbb{N}$ maka $f p b(|x|,|y|)=|y| \neq 1$, sehingga berdasarkan definisi graf koprima, titik $x, y$ tidak bertetangga. Selanjutnya, karena $|(1)|=1$ diperoleh $f p b(|(1)|,|z|)=1$ untuk setiap $z \in H$. Akibatnya untuk setiap unsur di $H$ yang merupakan titik di $T_{H}$ bertetangga dengan (1). Oleh karena itu, graf koprima $T_{H}$ merupakan graf bintang $K_{1,|H|-1}$.

\section{Kesimpulan}

Berdasarkan hasil dan pembahasan pada bab sebelumnya didapatkan bahwa karakteristik graf koprima dari subgrup di grup simetri yaitu setiap subgrup di grup simetri yang berorde hasil perkalian dari dua bilangan prima yang berbeda membentuk graf 3-partit lengkap, dan setiap subgrup di grup simetri yang memiliki unsur-unsur berorde sama atau kelipatannya membentuk graf bintang.

\section{Ucapan Terima kasih}

Penulis menngucapkan terima kasih kepada Dr. Lyra Yulianti, Monika Rianti Helmi, M.Si , dan Dr. Haripamyu yang telah memberikan kritik dan saran sehingga makalah ini dapat diselesaikan dengan baik.

\section{Daftar Pustaka}

[1] Bondy, J.A., Murty U.S.R., 1976, Graph Theory with Applications, London

[2] Conrad, K., 2014, Orders of Elements in a Group, www.math.uconn.edu/kconrad/blurbs/grouptheory/order.pdf

[3] Fraleigh, J.B., 2003, A First Course in Abstract Algebra, Edisi ke-7, AddisonWesley Publishing Company, United States of America

[4] Gallian, J.A., 2010, Contemporary Abstract Algebra, Edisi ke-7, Brooks/Cole, Cengage Learning, United States of America

[5] Hungerford, T.W., 1974, Algebra, Springer-Verlag New York Inc, New York

[6] Irnawati, 2016, Graf Konjugasi dari Subgrup di Grup Simetri, Skripsi di Universitas Islam Negeri Maulana Malik Ibrahim, tidak diterbitkan

[7] Kurzweil, H., Stellmacher, B., 2004, The Theory of Finite Groups An Introduction, Springer-Verlag, New York

[8] Ma, X., Wei, H., Yang, L., 2014, The Coprime Graph of A Group, International Journal of Group Theory, 3(3): 1-16

[9] Sattanathan, M., Kala, R., 2009, An Introduction to Order Prime Graph, Int. J. Contemp. Math. Sci, 4(10): 467-474

[10] Syarifudin, A.G., 2020, Karakteristik Graf Koprima dari Grup Dihedral dan Setiap Subgrupnya, Universitas Mataram, tidak diterbitkan 